\title{
Valorización de Cáscaras de Huevo Como Suplemento de Calcio en Pasta Tipo Fettuccine
}

\author{
Ricardo Rosas ${ }^{\text {a*}}$, Néstor O. Gómez a , Elizabeth Tomás a, Angélica Hernández a , Javier D. Dorantes ${ }^{\text {a }}$, Bryan García a, \\ Gabriela A. Vázquez ${ }^{\mathrm{b}}$
}

${ }^{a}$ Alumnos de la Licenciatura de Química en Alimentos, Área Académica de Química, Instituto de Ciencias Básicas e Ingeniería, UAEH.

${ }^{b}$ Profesora investigadora del Área Académica de Química, Instituto de Ciencias Básicas e Ingeniería, UAEH.

\section{Resumen}

La industria alimentaria genera cada año muchas toneladas de cáscaras de huevo, que por lo general no son aprovechadas pero que tienen un gran potencial como suplemento alimenticio. La pasta es un alimento de gran aceptación a nivel mundial y forma parte de los hábitos alimenticios de muchas personas porque es relativamente económica, versátil, de fácil preparación y almacenamiento. Por lo tanto, se le consideró un producto óptimo para evaluar la adición de cáscara de huevo como fuente de calcio. En este proyecto de clase, se elaboró una pasta tipo fettuccine a partir de harina de trigo y se le adicionó cáscara de huevo en polvo. Posteriormente se determinó la presencia de Salmonella y se determinó el contenido de calcio en la pasta. Se obtuvo un porcentaje promedio de $9.06 \%$ de calcio, que fue muy superior al de una pasta comercial $(0.035 \%)$. Al no haberse detectado la presencia de Salmonella, se concluyó que la cáscara de huevo puede aumentar el valor nutricional de este popular alimento sin que se comprometa su inocuidad.

Palabras Clave: pasta, cáscara de huevo, residuos, calcio, Salmonella.

\section{Introducción}

La pasta es un alimento preparado con una masa cuyo ingrediente básico es la harina de trigo, mezclada con agua, y a la cual se puede añadir sal, huevo $u$ otros ingredientes. Normalmente se utiliza la especie Triticum durum (trigo duro) — variedad típica del área mediterránea- en su elaboración. Para obtener esta harina solo se emplea una parte del grano del cereal, el endospermo, rico en almidón y gluten, lo que le confiere una mayor capacidad de moldeado (FEN, 2017).

La pasta es un alimento con alta aceptabilidad a nivel mundial debido a que forma parte de los hábitos alimenticios de muchas poblaciones y es relativamente económico, versátil, de fácil preparación y almacenamiento. Desde un punto de vista nutricional, las pastas son reconocidas como una fuente de carbohidratos complejos, con poca grasa y de baja calidad proteica, debido a que la sémola es su principal constituyente (Ramírez-Chicas, 2015).

Por otra parte, de acuerdo con estudios realizados por Belitz (2009), la cáscara de huevo es rica en minerales como el carbonato de calcio ( $95 \%$ en peso de la corteza), carbonato de magnesio $(1 \%)$ y fosfato de calcio $(1 \%)$. Del carbonato de calcio presente en la cáscara, un $36.9 \%$ se encuentra de forma absorbible para el cuerpo humano (Gómez, 2011).

El calcio es un mineral indispensable para varios procesos del organismo tales como la formación de los huesos y los dientes, la contracción muscular y el funcionamiento del sistema nervioso. El 95\% del calcio de nuestro cuerpo se encuentra en los huesos y dientes y al no consumir este nutriente, estos se debilitan (Ramírez-Chicas, 2015). Para los individuos cuyo consumo de alimentos ricos en calcio es limitado, el uso de la cáscara de huevo en alimentos, además de darle un valor agregado representa una alternativa para contribuir de forma significativa al requerimiento diario de calcio (Ramírez-Chicas, 2015).

El presente estudio tiene como objetivo la adición de cáscaras de huevo a pasta elaborada con harina de trigo, como una fuente de calcio para los individuos cuyo consumo de alimentos ricos en calcio es limitado.

\section{Materiales y métodos}

\subsection{Materiales}

La materia prima utilizada fue harina de trigo comercial; las cáscaras de huevo fueron donadas por la panadería "Choux" (Mineral de la Reforma, Hgo.). Se emplearon también extractos de jitomate y espinacas y huevo.

\subsection{Preparación del polvo de cascarón de huevo}

Las cáscaras de huevo se lavaron y desinfectaron por inmersión en una solución a 200 ppm de hipoclorito de sodio durante 15 minutos con agitación constante. Luego de la desinfección, las cáscaras de huevo se sumergieron en agua a $80{ }^{\circ} \mathrm{C}$ durante 10 minutos para retirar los restos del hipoclorito de sodio. Las cáscaras de huevo desinfectadas se colocaron sobre papel aluminio y se llevaron a desecación en una estufa

* Autor en correspondencia.

Correos electrónicos: rikrdo.rosasjmz@hotmail.com 
a $100{ }^{\circ} \mathrm{C}$ durante 4 horas. Posteriormente se molió el cascarón seco con un molino manual para granos. Por último se tamizó en un tamiz de $250 \mu \mathrm{m}$.

\subsection{Preparación de los extractos de jitomate y espinaca}

Se colocaron en dos recipientes 300 gramos de espinaca y de jitomate por separado, y se desinfectaron empleando una solución a 200 ppm de hipoclorito de sodio. Posteriormente las espinacas se colocaron a ebullición en un recipiente con agua purificada, dos minutos después de la ebullición se trituraron con ayuda de una licuadora. Los jitomates se licuaron crudos.

\subsection{Preparación de la pasta}

Se pesaron $500 \mathrm{~g}$ de harina de trigo, $20 \mathrm{~g}$ de extracto y $5 \mathrm{~g}$ de polvo de cáscara de huevo. Primero se mezclaron los ingredientes secos de forma manual. Posteriormente se agregó un huevo por cada $100 \mathrm{~g}$ de harina y se adicionaron los extractos; luego se homogenizó la mezcla hasta obtener una masa viscosa y elástica. Luego se pasó la masa por la laminadora Homemak para reducir el tamaño de la masa (grosor de $0.2 \mathrm{~cm}$ y un ancho de $0.7 \mathrm{~cm}$ ). Por último, la pasta se secó a temperatura ambiente sobre láminas de papel aluminio durante tres días (Figura 1)

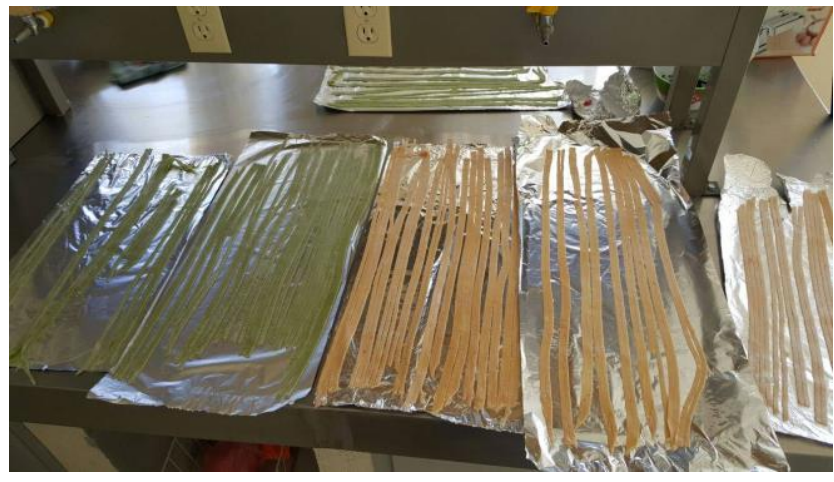

Figura 1. Imagen de la pasta elaborada.

\subsection{Determinación de calcio}

Para la determinación de calcio se pesaron 5 gramos de pasta seca previamente triturada (por triplicado), que después se colocaron en crisoles de porcelana. Las muestras se introdujeron primero a una estufa durante 4 horas a $100^{\circ} \mathrm{C}$ y posteriormente a una mufla durante 4 horas a $800^{\circ} \mathrm{C}$. Una vez obtenidas las cenizas, se tomaron 3 muestras de un gramo cada una y se colocaron en matraces Erlenmeyer de $250 \mathrm{ml}$ y se les adicionaron $50 \mathrm{ml}$ de agua. Se realizaron valoraciones con EDTA $0.01 \mathrm{M}$ con negro de eriocromo T como indicador.

\subsection{Determinación de Salmonella en la pasta}

Primero se prepararon $900 \mathrm{ml}$ de agua peptonada al $1 \%$ y se le adicionaron 100 gramos de pasta seca y triturada. Posteriormente se realizaron 6 diluciones y se sembraron cada una de las diluciones en agar Salmonella-Shigella mediante la técnica de estría cruzada. Las placas se incubaron a $37^{\circ} \mathrm{C}$ durante 24 horas.

\section{Resultados y discusión}

\subsection{Determinación de calcio}

Como se puede observar en la Tabla 1, se obtuvo un valor promedio de calcio de 9.06 gramos por cada 100 gramos de muestra de la pasta elaborada con harina de trigo y enriquecida con cáscaras de huevo. De acuerdo con INCAP (2007), el porcentaje de calcio presente en una pasta de trigo elaborada con huevo es de $0.035 \%$ ( $35 \mathrm{mg}$ por cada $100 \mathrm{~g}$ de muestra), por lo que se puede observar que la pasta realizada en este proyecto presenta un porcentaje mayor de calcio que las pastas comerciales. Según Belitz (2009), y como se mencionó antes, esto se debe a que la cáscara de huevo es rica en minerales. Lo anterior representa una gran ventaja al consumir esta pasta, debido a que el calcio es un mineral indispensable para varios procesos del organismo, tales como la formación de los huesos y los dientes, la contracción muscular y el funcionamiento del sistema nervioso, entre otros (Ramírez-Chicas, 2015). Así, el uso de la cáscara de huevo en alimentos puede contribuir de forma significativa al requerimiento diario de calcio, el cual de acuerdo con la Norma NOM-051-SCFI/SSA1-2010 es de 900 mg al día.

Tabla 1. Determinación del contenido de calcio en la pasta enriquecida con cascarón de huevo.

\begin{tabular}{|c|c|c|c|c|}
\hline Muestra & $\begin{array}{l}\text { Volumen de } \\
\text { EDTA gastado } \\
(\mathrm{mL})\end{array}$ & $\begin{array}{l}\text { Molaridad } \\
\text { del EDTA }\end{array}$ & $\%$ de Calcio & $\begin{array}{l}\% \text { de Calcio } \\
\text { promedio }\end{array}$ \\
\hline 1 & 23 & 0.1 & 9.2 & \multirow{3}{*}{9.06} \\
\hline 2 & 22 & 0.1 & 8.8 & \\
\hline 3 & 23 & 0.1 & 9.2 & \\
\hline
\end{tabular}

\subsection{Análisis microbiológico}

De acuerdo con la FDA (2016), los cascarones de huevo limpios y sin rajaduras pueden contener Salmonella spp., que es una bacteria que puede causar una intoxicación alimentaria. La mayoría de las personas infectadas con Salmonella desarrollan diarrea, fiebre, calambres abdominales y vómitos 12 a 72 horas luego de la infección. Los síntomas generalmente duran entre 4 y 7 días. Es por ello que durante este estudio se llevó a cabo la determinación de Salmonella en la pasta tipo fettuccine, debido a que durante su elaboración se empleó harina de cáscara de huevo. Para el análisis microbiológico se empleó agar Salmonella-Shigella (Figura 2), el cual es un medio selectivo y diferencial utilizado para el aislamiento de Salmonella spp. y algunas especies de Shigella spp. a partir de alimentos y otros materiales en los cuales se sospeche su presencia (Laboratorios Britania S.A., 2015).

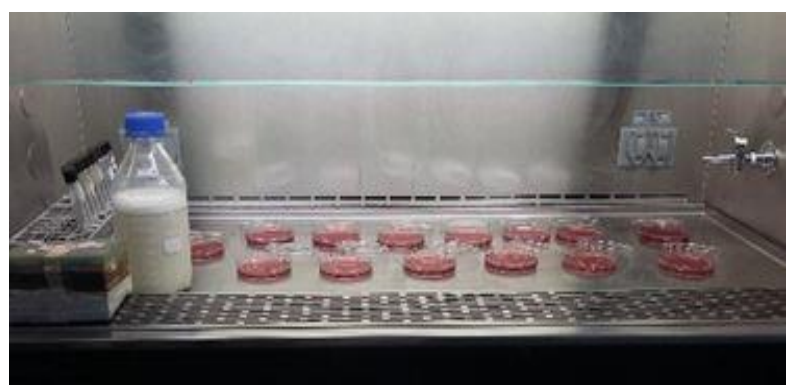

Figura 2. Cajas con agar Salmonella-Shigella antes de la siembra. 
Las cajas inoculadas con la muestra se incubaron a $37^{\circ} \mathrm{C}$ durante 24 horas. Posterior a la incubación no se observó crecimiento de colonias sobre el agar (Figura 3) por lo que se puede deducir que el proceso de desinfección con hipoclorito de sodio, al cual fueron sometidas las cáscaras de huevo, se realizó de manera eficiente, esto es debido a que los compuestos clorados son bactericidas. Sus formas más utilizadas son: hipoclorito de sodio (en solución acuosa) o de calcio (en tabletas). El principio activo de estos se basa en la liberación de cloro molecular, que en presencia de agua se combina con esta para formar ácido hipocloroso, el cual es un fuerte agente oxidante (García-Cortés, 2004).
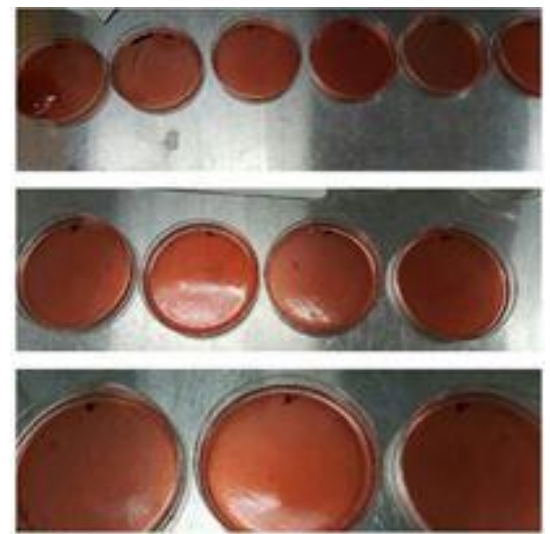

Figura 3. Cajas de Petri sin crecimiento de colonias.

\section{Conclusión}

La adición de cáscaras del huevo a pasta tipo fettuccine mostró ser una alternativa para que aumente al consumo de alimentos ricos en calcio. Al mismo tiempo, se valorizaría un residuo muy abundante en México, que actualmente no se aprovecha significativamente. La pasta, al ser un alimento popular entre la población mexicana, permite la adición de este suplemento, lo que ayudaría a incrementar la ingesta de calcio y así favorecer a la nutrición adecuada de las personas. Sin embargo, es necesario garantizar la desinfección adecuada de las cáscaras de huevo para que no se comprometa la inocuidad del producto.

\section{English Summary}

Valorization of eggshells as calcium supplement of fetuccine-type pasta

\begin{abstract}
Food industry generates enormous quantities of eggshells per year, which are not fully harnessed in spite of their potential as nutritional supplement. Pasta is a common part of the diet of millions of people because it is cheap, versatile and easy to be stored and prepared. In this class project, a fettuccine-type pasta was prepared and supplemented with powdered eggshells. The content of calcium and the presence of Salmonella were evaluated in the obtained pasta. We measured a mean content of $9.06 \mathrm{~g}$ of calcium per $100 \mathrm{~g}$ of product, which is significantly higher than the content of this nutrient in commercially-available pasta $(0.035 \mathrm{~g} / 100 \mathrm{~g})$. As Salmonella was not detected, it was concluded that eggshells can be valorized as calcium supplement in pasta without jeopardize the safety of the product.
\end{abstract}

Keywords:

Pasta, eggshells, waste, calcium, Salmonella

\section{Referencias}

Belitz, H., 2009. Food Chemistry. Springer, Heidelberg, Alemania.

FEN, 2017. Fundación Española de la Nutrición. Tomado de: http://www.fen.org.es/mercadoFen/pdfs/pasta.pdf

FDA, 2016. Food and Drug Administration. Tomado de: https://www.fda.gov/downloads/Food/FoodborneIllnessContaminants/ UCM278447.pdf

García-Cortés, V., 2004. Introducción a la Microbiología, $2^{\mathrm{a}}$ edición. EUNED, Costa Rica.

Gómez, D. L., 2011. Cuantificación de calcio en soluciones caseras que contienen cáscara pulverizada de huevo de gallina (Gallus gallus). Tesis de licenciatura. Universidad de San Carlos de Guatemala, pp. 39.

INCAP, 2007. Tabla de composición de alimentos de Centroamérica. Guatemala.

Laboratorios Britania S.A., 2015. Britanialab. Tomado de: http://www.britanialab.com/productos/B02138\%20REV\%2001SALMONELLA\%20SHIGELLA\%20AGAR.pdf

NOM-051-SCFI/SSA1-2010. Especificaciones generales de etiquetado para alimentos y bebidas no alcohólicas preenvasados - Información comercial y sanitaria.

Ramírez-Chicas, A., 2015. Evaluación de características físicas, químicas y sensoriales de pastas fettuccine con sustitución parcial de la harina de trigo por almidón de yuca y cáscara de huevo. Tesis de licenciatura. Escuela Agrícola Panamericana, Honduras. 